\title{
Broad definitions of enforcement are unhelpful for understanding evolutionary mechanisms of cooperation
}

\author{
Sacha C. Engelhardt $\mathbb{D}^{\star}$ and Michael Taborsky $\mathbb{}$ \\ ARISING FROM J. A. Ågren et al. Nature Ecology \& Evolution https://doi.org/10.1038/s41559-019-0907-1 (2019)
}

A recent review brings much needed attention to the generally underappreciated importance of enforcement for the evolution of cooperation at all levels of biological organization ${ }^{1}$. Our understanding of the evolution of cooperation is limited by a focus on kin selection ${ }^{2}$ rather than on explanations based on direct fitness benefits ${ }^{3,4}$ and enforcement ${ }^{1,5}$.

Ågren et al. ${ }^{1}$ highlighted that enforcement, one of four evolutionary mechanism that can generate evolutionarily stable levels of cooperation $^{6}$, can affect interactions between parties with conflicting fitness interests at all levels of organization from intracellular to societal. However, their definition of enforcement as "an action that evolves, at least in part, to reduce selfish behaviour within a cooperative alliance" seems to be an impractical "umbrella definition' that covers virtually the entire field of cooperation, not merely that explained by shared genes. This renders alternative evolutionary explanations indistinguishable, which is, in our view, detrimental to a profound comprehension of the evolution of cooperation. For instance, Ågren et al. ${ }^{1}$ explicitly include reciprocal altruism and tit-for-tat, partner choice, interspecific mutualisms and apoptosis (which is classified as self-enforcement) in their enforcement concept. We maintain that such a broad perception introduces two unfortunate flaws.

The first is a semantic problem. Transforming everyday terms into technical language with a specific meaning that deviates from its common connotation leads to misunderstandings within and especially between fields ${ }^{7}$. Enforcement is commonly used to refer to an action involving manipulation by force to the benefit of an actor at the expense of a receiver, and this meaning can be maintained regardless of whether we are interested in the action of an individual, cell or molecular element.

The second is a conceptual problem: most social interactions involve some sort of manipulation, because fitness interests rarely converge completely between interaction partners ${ }^{8,9}$. Nevertheless, not all manipulation is enforcement. It is essential, in fact, to differentiate between alternative forms of manipulation that involve either enforcement or the provision of incentives. Both are meant to increase the propensity of the recipient of an action to behave in the actors' interest. In the case of enforcement, this manipulation works if the recipient fares better by conceding to the coercion-that is, the costs of being subjected to the force are higher than yielding the requested service to the oppressor. In contrast, if an actor provides an incentive to a recipient, the latter will behave in the former's interest because this act will provide a benefit in itself. Hence it makes sense to differentiate whether an actor imposes costs to a receiver to 'enforce' a beneficial response, or provides an enticement to a receiver to 'incentivize' a response, which will then be beneficial to both. The usefulness of this differentiation has been illustrated by reproductive skew models developed to account for dominants either threatening eviction of subordinates, which is manipulation via enforcement, or conceding a share of reproduction to them as an incentive to remain in the association and continue to cooperate, which reflects manipulation via incentives ${ }^{10,11}$.

Received: 6 October 2019; Accepted: 19 December 2019;

Published online: 10 February 2020

\section{References}

1. Ågren, J. A., Davies, N. G. \& Foster, K. R. Enforcement is central to the evolution of cooperation. Nat. Ecol. Evol. 3, 1018-1029 (2019).

2. Hamilton, W. D. The genetical evolution of social behaviour. I. J. Theor. Biol. 7, 1-16 (1964).

3. Taborsky, M., Frommen, J. G. \& Riehl, C. The evolution of cooperation based on direct fitness benefits. Phil. Trans. R. Soc. B 371, 20150472 (2016).

4. Clutton-Brock, T. H. Cooperation between non-kin in animal societies. Nature 462, 51-57 (2009).

5. Clutton-Brock, T. H. \& Parker, G. A. Punishment in animal societies. Nature 373, 209-216 (1995).

6. Lehmann, L. \& Keller, L. The evolution of cooperation and altruism: a general framework and a classification of models. J. Evol. Biol. 19, 1365-1376 (2006).

7. Taborsky, M. Cooperation built the Tower of Babel. Behav. Process. 76, 95-99 (2007).

8. Dawkins, R. The Selfish Gene (Oxford Univ. Press, 1976).

9. Quiñones, A. E., van Doorn, G. S., Pen, I., Weissing, F. J. \& Taborsky, M. Negotiation and appeasement can be more effective drivers of sociality than kin selection. Phil. Trans. R. Soc. B 371, 20150089 (2016).

10. Johnstone, R. A. Models of reproductive skew: a review and synthesis. Ethology 106, 5-26 (2000).

11. Keller, L. \& Reeve, H. K. Partitioning of reproduction in animal societies. Trends Ecol. Evol. 9, 98-102 (1994).

\section{Author contributions}

S.C.E. and M.T. conceived, designed, drafted and reviewed the work.

\section{Competing interests}

The authors declare no competing interests.

\section{Additional information}

Correspondence and requests for materials should be addressed to S.C.E.

Reprints and permissions information is available at www.nature.com/reprints.

Publisher's note Springer Nature remains neutral with regard to jurisdictional claims in published maps and institutional affiliations.

(c) The Author(s), under exclusive licence to Springer Nature Limited 2020 